\title{
A Fuzzy Logic Approach to Assess Web Learner's Joint Skills
}

\author{
Mousumi Mitra \\ Dept. of CSE, Netaji Subhash Engineering College, Garia, Kolkata-700152, INDIA. \\ Email: mousumi.mtr@gmail.com \\ Atanu Das \\ Dept. of CSE, Netaji Subhash Engineering College, Garia, Kolkata-700152, INDIA. \\ Email: atanudas75@yahoo.co.in
}

\begin{abstract}
Skill assessment is an important but complicated task in the entire web based teaching and learning process. The learner's performance assessment has a strong influence on learners' approaches to learn and their learning outcomes like professional acceptability on desired skills. Most educators focus either on assessing a learner's technical skill set or nontechnical skill set, individually, rather than focusing on both the aspects. This paper bridges the gap by applying fuzzy logic approach to analyze a learner's joint skills incorporating both skills-set.

An already proven e-commerce website's evaluation technique has been chosen and applied in two situations of learner's skill assessment through case studies namely: technical skills evaluation, and non-technical skills evaluation. Experiments show that the learner's success depends on both sets of skill attributes. This work then proposed a novel method for skill assessment considering two (instead of one) sets of skill attributes invoking parallel or joint application of the technique. This new technique has also been analysed through a case study.
\end{abstract}

Index Terms-E-learning, fuzzy logic, joint-skill, skill assessment, competencies.

\section{INTRODUCTION}

Web-based education and training are now well established. It provides an environment to create interactive interfaces which can monitor every response made by the learner or the system. Students in web learning programs can receive learning materials online, access video lectures, attend videoconference classes and participate in chat room discussions. The effectiveness of such learning suffers due to lack of face-to-face interaction among students and faculty members. This gap is much prominent especially in technical and professional learning courses where development of skills is a major issue together with professional aptitudes. This gap can be abridged (to some extent) if these web learning systems can offer learner's tracking through the assessment of acquired skill sets in each and every stage of offering content.
Actual web based educational processes deal with uncertainty in human knowledge. Most educational systems use classical methods to handle vague information in the knowledge representation and decision making. Furthermore, fuzzy set theory $[1,5]$ incorporates precise techniques for solving such problems. These theories could be one of the choices for proper evaluation of a learner's performance among the available approaches like neural [3], Baysian [8] networks.

The purpose of this paper is to share the features of web-based learning technology and fuzzy logic theory to design an interactive online learning system. The system will check the learner's knowledge levels to provide the appropriate content. Contents are prepared to cope with diversified learners. The system will enable learner to move from one unit to the other according to his/her level assessed through test score.

\section{BACKGROUND}

[7] demonstrated different artificial intelligence (AI) based techniques for educational software development. Fuzzy logic as one of the AI technique, was developed to solve problems in which description of activities were imprecise, vague and uncertain. Thus it is applicable to solve engineering problems in expert systems including Intelligent Tutoring Systems (ITS). It has been widely used to solve problems in the evaluation and assessment process $[1]$. $[4,11]$ presented a fuzzy grading method that utilizes student's and instructor's performance measure to produce a fair mark distribution. [5] described a fuzzy logic approach to assess the outcomes of student-centered learning. [1] described a fuzzy logic technique to evaluate student's answer scripts. Traditional propositional and predicate logic do not allow for degrees of imprecision such as poor, average and good. Multi-valued logic consisting of unsatisfactory, satisfactory, average, good and excellent may be introduced here. This predicate sets are used in fuzzy logic implemented in fuzzy systems. In general, approximation or fuzzy reasoning is the presumption of a possible and imprecise conclusion out of a possible and imprecise initial set [2].

This work focused fuzzy logic technique for the learner's performance evaluation. A fuzzy logic based 
technique for "E-Commerce websites evaluation", proposed by [2] has been identified. This technique has been applied first in [6] for technical skills evaluation of web learners.

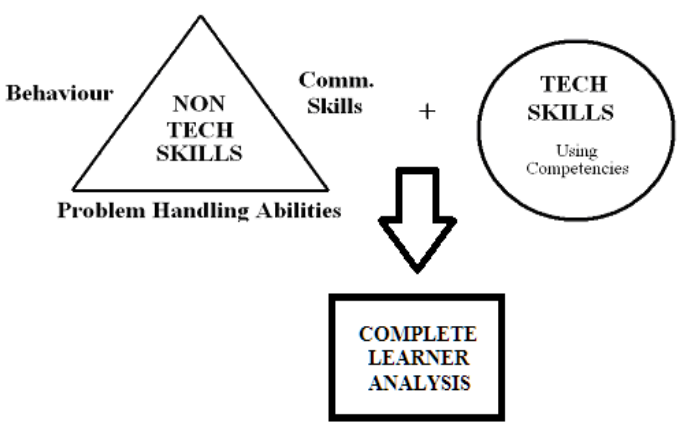

Fig.1.Representation of complete Learner Analysis

Under successful framework in this approach, the said method is proposed to be applied here in different situations of learner's performance evaluation through case studies namely: (a) technical skills evaluation (b) non-technical skills evaluation. Here technical skills evaluation involves fuzzy logic technique dealing with the specific set of data, that is, learner's score in the test. While non-technical skills evaluation involves fuzzy logic technique dealing with human thinking and human subjective judgments with incomplete and uncertain information. In other words, the final judgment term is provided based on different teacher's ratings. This approach provides the teachers with a flexible way to present their individual preferences which takes into consideration fuzzy assessment data.

[10] reviewed research trends in technology-based learning in a recent time (during 2000 to 2009). It is also observed that the considered web learning systems $[9,12]$ should not only consider technical or non-technical skillsset separately. They seem to be taken care together jointly. The proposed novel approach in this work namely "Joint Application of the Fuzzy Logic Technique" can address this problem and can assess the learner's professional acceptability (may be to the employers) besides individual performance evaluation on different skills-sets. It aims at encouraging learners to participate in the whole learning process and providing an open and fair environment for assessment. The fig. 1 presents the basic analysis structure for joint application.

\section{A. Considered Technique}

[2] provides e-commerce website evaluators a flexible way to present their evaluation based on fuzzy logic. It takes into consideration imprecise and uncertain assessment data in the evaluation process. This method is further illustrated, modified and applied in [6] for web learner technical skill evaluation. This method is explained below before further modification for joint application. It is based on mass voting, approximations and analysis with no chance of an exact value.

\section{B. Fuzzy Assessment Method}

As discussed, a website has several sub-features. For example, establish multiple communication channels feature include six sub-features: e-mail support, telephone support, frequently asked question, information updates, discussion forums with other users, experts and online chat with company's representatives. To get the evaluation of a website feature, evaluators need to consider all sub-features comprehensively. A fuzzy assessment method is presented below considering subfeatures.

Let $G=\left\{g_{1}, g_{2}, \ldots, g_{d}\right\}$ be a set of grades, in our case, $\mathrm{G}=\{$ excellent, very good, good, fair, poor $\}$ of a website feature and $\mathrm{C}$ be the set of sub-features . The evaluator's evaluation can be represented as fuzzy relation matrix E:

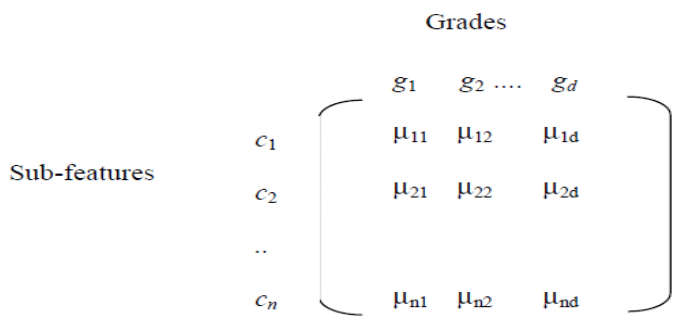

For a feature of website we derived the fuzzy evaluation relation $\mathrm{E}$ and fuzzy weight $\mathrm{W}$. The result is a fuzzy vector (evaluation vector), denoted as Y

$$
Y=W \circ E=\left(w_{1}, \cdots, w_{n}\right) \circ\left[\begin{array}{cccc}
\mu_{11} & \mu_{12} & \cdots & \mu_{1 d} \\
\mu_{21} & \mu_{22} & \cdots & \mu_{2 d} \\
\vdots & \vdots & & \vdots \\
\mu_{n 1} & \mu_{n 2} & \cdots & \mu_{n d}
\end{array}\right]=\left(y_{1}, y_{2}, \cdots, y_{d}\right)
$$

The concept of fuzzy weights comes into the picture because not all competencies are equally important or equally complex. So, the weights determine which competency would be more important and which can carry lesser importance. This would be internal to the system so as to prevent learners from manipulating the system.

According to the principal of fuzzy classification, we have $\mathrm{y}_{\mathrm{i}}=\sum\left(\mathrm{y}_{1}, \mathrm{y}_{2} \ldots \mathrm{y}_{\mathrm{d}}\right)$.

The considered technique has been applied in different situations of learner's performance evaluation through case studies namely: (a) technical skills evaluation (b) non-technical skills evaluation. The standards are mapped to a 3-tuple system for calculating Judgment Term for Technical Skill. The following table 1 presents that 3tuple.

Table 1. The Considered 3-Tuple

\begin{tabular}{|c|c|}
\hline Judgement Term & 3-tuple \\
\hline Beginner & $<1,0,0>$ \\
\hline Intermediate & $<0,2,0>$ \\
\hline Expert & $<0,0,3>$ \\
\hline
\end{tabular}


Table 4. 3-Tuple Considered in Example 3, Representing Equation (1)

\begin{tabular}{|c|c|c|}
\hline Competency & 3-tuple & $\mathbf{E}$ \\
\hline Competency 1 & $<1,0,0>$ & \multirow{1}{|c|}[\begin{array}{lll}{1}&{0}&{0}\\
{1}&{0}&{0}\\
{1}&{0}&{0}\\
{0}&{2}&{0}\\
{0}&{2}&{0}\end{array}]{} \\
\hline Competency 2 & $<1,0,0>$ & \\
\hline Competency 3 & $<1,0,0>$ & \\
\hline Competency 4 & $<0,2,0>$ & \\
\hline Competency 5 & $<0,2,0>$ & \\
\hline
\end{tabular}

Table 5. 5-Tuple Gradation System used in Non-Technical Skills Evaluation

\begin{tabular}{|l|c|}
\hline \multicolumn{1}{|c|}{ STATUS } & 5-TUPLE MAPPING \\
\hline Excellent & $<1,0,0,0,0>$ \\
\hline Greater than very good & $<0.3,0.7,0,0,0>$ \\
\hline Very Good & $<0,1,0,0,0>$ \\
\hline Less than very good & $<0,0.9,0.1,0,0>$ \\
\hline Greater than good & $<0,0.3,0.7,0,0>$ \\
\hline Good & $<0,0,0.6,0.4,0>$ \\
\hline Less than good & $<0,0,0.4,0.6,0>$ \\
\hline Greater than average & $<0,0,0,0.8,0.2>$ \\
\hline Less than average & $<0,0,0,0.2,0.8>$ \\
\hline Greater than poor & $<0,0,0,0,1>$ \\
\hline Poor & $<$ \\
\hline
\end{tabular}

And the pre- determined set of fuzzy weights (W) is $\{0.2,0.2,0.1,0.4,0.1\}$. From the equation $\mathrm{Y}=\mathrm{W} \circ \mathrm{E}$, his/her ultimate grading set would look like $\{0.2,0.2,0.1$, $0.8,0.2\}$. So, the evaluation vector i.e. fuzzy vector, denoted by $\mathrm{Y}=\{0.2,0.2,0.1,0.8,0.2\}$. So, his/her ultimate score is $0.2+0.2+0.1+0.8+0.2=1.5$. Therefore, suggestion of the faculty to the learner, viewing his/her technical performance would be: NEED TO IMPROVE.

\section{Case Study - 2: Non-Technical Skills Evaluation}

In case of a group of faculty, assessing a learner's nontechnical skills, the set of attributes they generally look into are:-

- Behaviour

- Communication skills

- Problem handling abilities

Case Study 2 shows that grades for the representations associated as part of equation (1) would indicate the standard that the learner is in currently, but in a more analogue format. The consideration here is that whether the learner is good enough or not is decided by voting among a panel of experts. Each tuple would signify what fraction of people voted for the learner, to belong to the corresponding status or level for that competency (Ref. equation 1). This will further be explained in the examples that follow. Sub-features indicate the competencies or topics which would provide the ground for judging the learner. "d" indicates the number of gradations we. At one point of time, there can be only one grade associated to a competency. The others should be zero at that point. "n" would represent the number of competencies or judging topics that the learner would be faced with.

Each of the skills can be rated as excellent, very good, good, average or poor. Now, let us consider that there is a panel of 10 interviewers. Each person is entitled to his own gradation. Now, all these gradations are aggregated and the skills of this learner are mapped to a 5-tuple system. Now, the gradation can be as shown in table 5 .

Like technical skill evaluation, weighted evaluation technique would be used. The total weight would be shared between all the competencies, as some competencies may be considered to be more important or complex than the others. Let A be the assessment matrix which is formed from the complete analysis of all the competencies in a tuple format and $\mathrm{W}$ be the matrix that would hold all of the weights for all of the competencies drawn in the Joint Assessment Matrix A

So, resultant decision matrix $\mathrm{R}=\mathrm{W} \circ \mathrm{A}$, where $\mathrm{R}_{\mathrm{i}}=\Sigma\left(\mathrm{W}_{\mathrm{j}} \times \mathrm{A}_{\mathrm{ij}}\right)$ from equation (2) where $\mathrm{j}=1$ to number of competencies, $\mathrm{i}=1$ to number of possible gradations (Good, Poor etc.). According to fuzzy classification, we have $\mathrm{R}_{\mathrm{i}}=\operatorname{MAX}\left(\mathrm{r}_{1}, \mathrm{r}_{2}, \mathrm{r}_{3}, \ldots ., \mathrm{r}_{\mathrm{d}}\right)$. So, in the end, the level or grade (Good, Average, Poor etc.) that would have the heaviest value would be considered the status or quality of non-technical skills of the learner. This would be further clear in the example given below.

Example: The average judgements given by the Interview panel are:-

- Behaviour: Greater than very good (3 voted excellent, 7 voted very good). So, going by fractions, 0.3 of total people consider the learner to be excellent and 0.7 consider the learner to be very good.

- Communication skills: Good. Again, going by fractions, all the people consider the learner to be good.

- Problem handling abilities: Less than average (8 voted average, 2 voted poor). Now, going by fractions, 0.8 of total people consider the learner to be average and 0.2 of them consider the learner to be poor.

So, the joint assessment matrix or the fuzzy relation is shown in table 6.

Now, the predetermined fuzzy weights assigned to each of the criteria mapped in a matrix format are $\{0.3$, $0.2,0.5\}$. So, $\mathrm{W}=\{0.3,0.2,0.5\}$ and $\mathrm{A}=$ joint assessment matrix (shown in the $5 \times 3$ table above). So, resultant decision matrix $\mathrm{R}=\mathrm{W}{ }^{\circ} \mathrm{A}$, where $\mathrm{R}_{\mathrm{i}}=\Sigma\left(\mathrm{W}_{\mathrm{j}} \mathrm{X} \mathrm{A} \mathrm{A}_{\mathrm{ij}}\right)$ where $j=1$ to 3 for each $i=1$ to 5 . According to fuzzy classification, we have $R_{i}=\operatorname{MAX}\left(r_{1}, r_{2}, r_{3}, \ldots ., r_{d}\right)$. So, the evaluation vector or the fuzzy vector is $\{0.09,0.21$, $0.2,0.4,0.1\}$. Now, since 0.4 is the highest value and it belongs to the grade "Average", the suggestion of the faculty to the learner, viewing his/her non-technical performance is AVERAGE. 
Table 6. Joint Assessment Matrix for the Fuzzy Relation

\begin{tabular}{|l|c|c|c|c|c|}
\hline & Excellent & $\begin{array}{l}\text { Very } \\
\text { Good }\end{array}$ & Good & Average & Poor \\
\hline Behaviour & 0.3 & 0.7 & 0 & 0 & 0 \\
\hline $\begin{array}{l}\text { Comm. } \\
\text { Skills }\end{array}$ & 0 & 0 & 1 & 0 & 0 \\
\hline $\begin{array}{l}\text { Problem } \\
\text { Handling }\end{array}$ & 0 & 0 & 0 & 0.8 & 0.2 \\
\hline
\end{tabular}

\section{Proposed New Methodology}

The proposed methodology in this paper is a joint application of the fuzzy logic technique.

\section{A. Motivation}

It has been observed that the learner's success depends on different sets of attributes of skills, like technical and non-technical skill-sets. It is observed that in the real world, people considered evaluation of both technical and non-technical skills-sets jointly, rather than individually.

This research then proposed a novel method for addressing the learner's performance evaluation in the consideration of both sets of attributes adopting parallel application of the said fuzzy logic technique. This would help the learners get a complete view of their current status at all levels, and where he/she needs to put his/her focus can be analysed, thus, providing complete development of the learner.

\section{B. Explanation}

Technical skills evaluation of the learner focuses on fuzzy logic, dealing with an exact and definite value, which is the learner's score. The judgement term for a learner's technical performance is provided based on his score and pre-determined fuzzy weights. But, nontechnical skills evaluation of the learner focuses on fuzzy logic dealing with individual preferences of each evaluator, which takes into consideration imprecise and uncertain data. An approximation is made based on the views of the group of faculty and then calculation is done using the pre-determined fuzzy weights to provide the judgement term for his/her non-technical performance.

To get an overall view of a learner's performance, teachers need to look into both the technical and nontechnical aspects of the learner. Here, first the technical skills of the learner and then the non-technical skills are analysed and then the status of the learner is judged. Now, the following three judgements need to be considered to provide a joint and complete analysis of a learner's performance:-

- Technical judgment

- Non-technical judgment

- Joint judgment

Only then the learner would be able to know where he/she stands from the entire perspective and improve himself/herself accordingly.

The parallel application of the technique helps to assess a learner's acceptability besides individual performance evaluation on different skills-set. The major benefit of the proposed approach is providing flexibility to the learner by permitting them to prepare themselves in different skills-set (e.g. technical and non-technical) for a better professional guidance.

\section{Case Study - 3: Joint Skills Evaluation}

When creating a joint review for a learner, we look at his/her various attributes, like

- Technical expertise over various competencies.

- Non-Technical expertise

- Behaviour

- Communication skills

- Problem handling abilities

So, when a learner's joint skill analysis is to be done, we need to consider the technical and non-technical aspects of the learner. Technical aspects can be measured using a test which would give us a definite set of scores from where, we can use our own fuzzy calculations to judge the learner. So, the fuzzy score decides the judgement term. But, to measure the non-technical aspects of the learner, approximation is done based on individual preferences of each teacher. So, the judgement term is decided, from a set of judgement, using fuzzy calculations.

For example: Now, let us consider the technical score (T) of the learner is 1.5 (fuzzy score using fuzzy logic, as explained in Case Study 1).

For the non-technical analysis, we have a 5-tuple system, whose 5-tuples are: EXCELLENT, VERY GOOD, GOOD, AVERAGE and POOR. To calculate the joint score, each of them is given a value. Say, EXCELLENT $=5.0$, VERY GOOD $=4.0$, GOOD $=3.0$, AVERAGE $=2.0$ and $\mathrm{POOR}=1.0$

So, after all the calculations for the non-technical skills of the learner (as explained in Case Study 2), if the judgement of the faculty for the learner is AVERAGE, his non-technical score $(\mathrm{N})$ is 2.0 .

The joint score of the learner is calculated as: $\mathrm{O}=\mathrm{T}+\mathrm{N}$.

Judgement decision for joint skills analysis, as set by the faculty, is shown below:

$$
\begin{aligned}
& \text { If (jointScore }>=7.0) \\
& \text { jointJudgment }=\text { "AWESOME } \\
& \text { PERFORMER". }
\end{aligned}
$$

Else if (jointScore $>=4.5$ ) jointJudgment $=$ "GOOD PROSPECT. NEED TO GIVE MORE EFFORT."

Else

jointJudgment = "POOR PERFORMANCE".

So, in this case, the joint score of the learner is $1.5+2.0=3.5$. Hence, the joint rating of the learner is POOR PERFORMANCE.

\section{Algorithm: Complete Joint Skills Evaluation}

Calculation of Joint skill can be briefly covered using the following steps:- 
Step 1: Fetch the competency status (beginner, intermediate, expert) of each competency from the DB.

Step 2: Calculate the score based on the pre-defined weights. basis.

Step 3: Determine the Technical Judgment on that

Step 4: Fetch the learner's profile from the DB.

Step 5: Calculate the score of each of the non-technical competency types (behaviour, comm. skills, problem handling).

Step 6: Calculate the list of all non-tech scores under each and every category (excellent, very good, good, average and poor) for each competency type.

Step 7: Calculate maxNonTechScorePosition which is the position of the highest score from the list of non-tech scores. basis.

Step 8: Determine the Non-Technical Judgment on that

Step 9: Calculate the maxNonTechScorePosition

$$
\begin{aligned}
& \text { If } \operatorname{maxNonTechScorePosition}=0 \text { ? nonTechScore }= \\
& 0.0
\end{aligned}
$$

if $\operatorname{maxNonTechScorePosition}=1$ ? nonTechScore $=5.0$

if $\operatorname{maxNonTechScorePosition}=2$ ? nonTechScore $=4.0$

if $\operatorname{maxNonTechScorePosition}=3$ ? nonTechScore $=3.0$

if $\operatorname{maxNonTechScorePosition}=4$ ? nonTechScore $=2.0$

Else, set nonTechScore $=1.0$

Step 10: Calculate the jointScore, jointScore $=$ nonTechScore + score from technical analysis.

Step 11: Determine jointJudgement

If jointScore $>7.0$ ? Set jointJudgement $=$ "AWESOME PERFORMER"

Else if jointScore $>4.5$ ? Set jointJudgement $=$ "GOOD PROSPECT. NEED TO GIVE MORE EFFORT."

Else Set jointJudgement $=$ "POOR PERFORMANCE"

Step 12: Display techJudgment as the fuzzy judgment for technical analysis.

Step 13: Display nonTechJudgement as the fuzzy judgment for non-technical analysis.

Step 14: Display jointJudgement as the fuzzy judgment for joint analysis.

\section{SYSTEM EVALUATION \& DisCUSSIONS}

A prototype of the proposed fuzzy-based web-learning system has been developed and tested to substantiate the performance of proposed novel learner's assessment technique. 3 years (2nd, 3rd and 4 th) of undergraduate engineering students from the same disciplines were considered as learners in this test. At the end of semester a self test was performed by the learner to check the learner's joint skill combining technical and nontechnical attributes. In this experiment, a set of questions consisting of $50 \mathrm{MCQ}$ questions covering both skills attributes were served subject to time constraints. Each question was categorized with respect to technical and non-technical skills attributes. The answer sheets were analysed with respect to individual question categories. The salient observations on the performance scores of the learners along with the feedback analysis are as follows.

Approximately $18 \%$ learners remained in the same learning levels. Learner's scores ranged from $52 \%$ to 95\%. Learners across all years (i.e. different knowledge levels) performed better in technical questions as expected from engineering students. While separately considering the non-technical skills evaluation, 4th year student scored higher than other two years in respect to problem handling and communication skills. This is possibly owing to the higher maturity levels of these students. On the other hand, 2nd year students perform better in behavioural skill than other two years. This may be because of growing impatience with increasing age.

The developed system was also compared with respect to some ITS developed [1] by us and other online available e-learning systems. On analysing the feedback of the students, the following observations may be noted. The effectiveness of the Web-Based Training (WBT) mainly depends upon (1) simulation of the operational aspects of the topic, (2) conceptual simulation and (3) information, loops of presentation and learning test. To make the WBT more effective, the developers should focus on (1) interactive learning method, (2) feedback and (3) reinforcement. Critical analysis of the feedbacks along with the comments there in prompted us to check some more WBT available. It was observed that the characteristics of the WBT that go wrong were (1) cultural difference, (2) lack of interactivity, (3) lack of proper navigation, (4) the absence of feedback, (5) the lack of review and remediation. WBT product quality mostly suffers due to (1) lack of expertise in learning theory and (2) lack of presence of related multimedia objects or overdose of them. That's why, possibly, the WBT does not help to increase knowledge retention and to acquire the permanent skill of both type.

Present study also tried to quantify the learner's feeling about their satisfaction and self improvement besides qualitative comparison with other contemporary learning system. The following table 7 demonstrated the percentage of learners' feeling with respect to the above issues analysed through feedbacks (questions asked like satisfied or not, noticed self-improvement or not) taken while undergone training through the given learning systems stated in the columns.

Table 7. Percentage of Learners' Feeling with Respect to Considered Learning Systems

\begin{tabular}{|l|c|c|c|c|c|}
\hline & $\begin{array}{c}\text { E- } \\
\text { Learning } \\
\text { without } \\
\text { Intelligent } \\
\text { Levelling }\end{array}$ & $\begin{array}{c}\text { Consider } \\
\text { ed ITS } \\
\text { by [1] }\end{array}$ & $\begin{array}{c}\text { Web } \\
\text { Learning } \\
\text { Sys. } \\
\text { with } \\
\text { only } \\
\text { Technic } \\
\text { al Skill } \\
\text { Evaluati } \\
\text { on }\end{array}$ & $\begin{array}{c}\text { Web } \\
\text { Learning } \\
\text { Sys. with } \\
\text { only Non- } \\
\text { Technical } \\
\text { Skill } \\
\text { Evaluatio } \\
\text { n }\end{array}$ & $\begin{array}{c}\text { Web } \\
\text { Learning } \\
\text { System } \\
\text { with } \\
\text { Proposed } \\
\text { Joint Skill } \\
\text { Evaluation }\end{array}$ \\
\hline $\begin{array}{l}\text { Satisfac } \\
\text { tion }\end{array}$ & $88 \%$ & $76 \%$ & $82 \%$ & $85 \%$ & $87 \%$ \\
\hline $\begin{array}{l}\text { Self- } \\
\text { Improv } \\
\text { ement }\end{array}$ & $72 \%$ & $78 \%$ & $83 \%$ & $80 \%$ & $93 \%$ \\
\hline
\end{tabular}


It is observed from table 7 that the proposed web learning system provided significant enrichment in the self-improvement issue with respect to other considered learning systems. It may also be noted that the considered learning systems perform almost similarly with respect to learner's satisfaction issue.

\section{CONCLUSION AND FUTURE SCOPE}

Online learning systems offer learners with the flexibility to balance study, work and personal commitments similar to other e-commerce activity while staying engaged in some other activities. This research identified a fuzzy logic based technique for e-commerce web-site evaluation. This technique is applied in different situations of learner's performance evaluation through case studies namely: technical skills evaluation and nontechnical skills evaluation. These implementations show that the said technique is valuable in those learners' performance assessment. It is observed that the proposed web learning system should consider technical and nontechnical skills development individually while there also exists a strong appeal to be taken care together jointly. The proposed novel approach in this paper namely "Parallel Application of the Fuzzy Logic Technique" can address this problem and can assess the learner's acceptability besides individual performance evaluation on different skills-set. The system can provide the learner appropriate content according to his/her knowledge level. The relative strength of fuzzy logic has been realized in comparison to other techniques based on neural or Baysian in learner's assessment.

The proposed technique has been analysed through a case study namely "Joint skills evaluation" which indicates that the technique works well for the purpose it has been designed. The most important benefit of the proposed approach is providing flexibility to the learner by permitting them to prepare themselves in different skills-sets (e.g. technical and non-technical) for a better professional guidance. Thus the proposed system can also be used for analysing the skill-gaps of learners towards their employability. This is possible because one can identify the weakness in any skill set between the considered two skill sets jointly. Students have evaluated the system through a questionnaire. The result demonstrates that such a system is effective for both students and passing graduates even for life-long learning. The present work also compared the proposed system with other contemporary systems and found some justifications behind the popularity of web-learning systems even in under developed countries having constraints of limited bandwidth of internet connection.

\section{REFERENCES}

[1] B. Ranjit, "An application of fuzzy set in students' evaluation," Fuzzy Sets and Systems, vol. 74, pp. 187194, 1995.

[2] D. Zhou and W. Huang, "Fuzzy Set Approach to Assessing E-commerce Websites," Proc. of the $10^{\text {th }}$
Americas Conf. on Inf. Sys., NY, pp. 2376-2383, August, 2004.

[3] H. Li and W. Wang, "Intelligent Tutoring System Based on Credal Networks and Learning Emotions," $2^{\text {nd }}$ Int. Workshop on Educ. Tech. and Comp. Sci., etcs, vol. 1, pp. 321-324, 2010.

[4] J. R. Echauz and G. J. Vachtsevanos, "Fuzzy Grading System,” IEEE Trans. Educ., vol. 38(2), pp. 158-164, 1995.

[5] M. Jian and D. Zhou, "Fuzzy set approach to the assessment of student-centered learning," IEEE Trans. on Educ., vol 43(2), pp. 237-241, 2000.

[6] M. Mitra and A. Das, "Applying A Fuzzy Technique For Web-Based Learner's Performance Evaluation," Proc. of N. Conf. on Control, Comm. \& Device Electronics, JIS Engg. College, WB, India, pp. 125-131, 2013.

[7] P. Brna, "Artificial intelligence in educational software: has its time come?" British J. of Educ. Tech., vol. 30, pp. 79-81, 1999.

[8] R. Bag and A. Das, "Developing an Intelligent Tutoring System following Bayesian Approach," Int. J. of Adv. Engg. \& App., vol. 2, pp. 114-119, 2010.

[9] T. D. Cochrane, "Critical success factors for transforming pedagogy with mobile Web 2.0,” British J. of Educ. Tech., vol. 45(1), pp. 65-82, 2014.

[10] Y. Hsu, H. N. J. Ho, C. Tsai, G. Hwang, H. C. Chu, C. Wang and N. Chen, "Research Trends in Technologybased Learning from 2000 to 2009: A content Analysis of Publications in Selected Journals," J. of Educ. Tech. \& Society, vol. 15(2), pp. 354-370, 2012.

[11] D. Bose, A. Das, "Using Fuzzy Trapezoidal Rule for Web Learner's Competence Assessment," Int. J. of Electronics and Communication Tech., (IJECT), Vol. 6 (1), spl-1, pp. 169-173, 2015.

[12] N. Cavus, "The application of a multi-attribute decisionmaking algorithm to learning management systems evaluation," British Journal of Educational Technology, vol.42, pp. 19-30, 2011.

\section{Authors' Profiles}

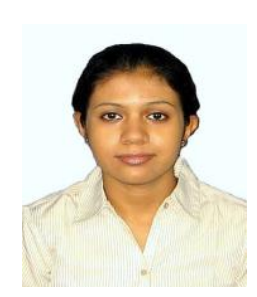

Mousumi Mitra - Born in 1987, received M. Tech (Comuter Science) in the year 2013, from Netaji Subhash Engineering College, under West Bengal University of Technology (WBUT) and B. Tech (Information technology) in the year 2010, from Saroj Mohan Institute of Technology, under WBUT, Kolkata, India. Presently, she has been involved in freelance software development for education and training. She has a publication in a reputed conference proceeding. Her research interests include education technology and software development besides fuzzy logic based techniques.

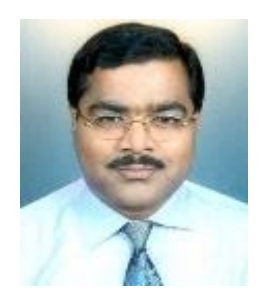

Dr. Atanu Das - was born in 1975, received his BSc (Math Hons.), MSc (Statistics) degrees from The University of Burdwan and ME \& PhD (Engg) degrees from Jadavpur University, India in the years 1996, 1998 and 2002 \& 2013 respectively. $\mathrm{He}$ is working as an Assistant Professor, CSE at Netaji Subhash Engineering College under West Bengal University 
Technology, Kolkata, India since 2002. He has more than 21 publications in reputed refereed journals, edited volumes and conference proceedings. His research interest includes image processing, multimedia and educational systems development, intelligent tutoring systems besides estimation and filtering for evolving systems.
Address for correspondence: Dr. Atanu Das, Department of CSE, Netaji Subhash Engineering College, Technocity, Garia, Kolkata-152, India. E-mail: atanudas75@yahoo.co.in.

Manuscript received June 24, 2015; accepted July 24, 2015.

How to cite this paper: Mousumi Mitra, Atanu Das,"A Fuzzy Logic Approach to Assess Web Learner's Joint Skills", IJMECS, vol.7, no.9, pp.14-21, 2015.DOI: 10.5815/ijmecs.2015.09.02 